\title{
Effect of a Physical Barrier on Adult Emergence and Egg Survival Associated with the Fungus Gnat, Bradysia sp. nr. coprophila (Diptera: Sciaridae), under Laboratory Conditions
}

\author{
Amy L. Raudenbush and Raymond A. Cloyd ${ }^{1}$ \\ Kansas State University, Department of Entomology, 123 Waters Hall, \\ Manhattan, KS 66506
}

\author{
Erik R. Echegaray \\ Oregon State University, Department of Crop and Soil Science, Corvallis, \\ OR 97331
}

Additional index words. greenhouse, growing medium, Growstones ${ }^{\mathrm{TM}}$ aggregates, pest management, physical control, rove beetle

\begin{abstract}
This study was conducted to assess the direct and indirect effects of Growstones ${ }^{\mathrm{TM}}$ aggregates, which are made from recycled glass, on fungus gnat, Bradysia sp. nr. coprophila (Diptera: Sciaridae), adult emergence, female egg-laying capacity, and egg survival. A series of experiments were performed under laboratory conditions to evaluate the effect of different sizes $(2.0$ to $10.0 \mathrm{~mm})$ of Growstones ${ }^{\mathrm{TM}}$ aggregates, layer thicknesses $(0.63$ to $3.18 \mathrm{~cm}$ ), and the use of the biological control agent, the rove beetle, Dalotia coriaria, along with different thicknesses $(1.27$ and $3.18 \mathrm{~cm})$ of small Growstones ${ }^{\mathrm{TM}}$ aggregates on fungus gnat adult emergence. For each experiment, Growstones ${ }^{\mathrm{TM}}$ aggregates were applied to the surface of the growing medium in $473-\mathrm{mL}$ polypropylene deli containers. This study demonstrated that the thickest $(3.18 \mathrm{~cm})$ layer of small $(2.0 \mathrm{~mm})$ Growstones $^{\mathrm{TM}}$ aggregates significantly reduced or delayed the emergence of fungus gnat adults. In addition, the thickest layer of small Growstones ${ }^{\mathrm{TM}}$ aggregates may have indirectly affected egg survival. However, the use of Growstones ${ }^{\mathrm{TM}}$ along with rove beetle adults did not significantly reduce fungus gnat adult emergence.
\end{abstract}

Fungus gnats are a commonly encountered insect pest of greenhouses (Dennis, 1978; Hamlen and Mead, 1979) and are typically a problem in moist environments such as those that occur in propagation or plug production (Cloyd, 2000). Adults cause minimal direct damage to plants; however, a single female Bradysia sp. nr. coprophila Lintner (Diptera: Sciaridae) can lay $\approx 96$ eggs on the surface of the growing medium (Meers and Cloyd, 2005). After eggs hatch, larvae feed on plant roots causing plant stunting, wilting, and possibly plant death (Jarvis et al., 1993; Springer, 1995; Wilkinson and Daugherty, 1970). In addition, indirect damage by larvae is associated with transmission of certain soilborne plant pathogens (Gardiner et al.,

Received for publication 27 Mar. 2014. Accepted for publication $28 \mathrm{Apr}$. 2014.

We thank Growstones, Inc. (Albuquerque, New Mexico) for providing the funds necessary to conduct this research. In addition, we thank Paula Costa of Growstones, Inc. (Albuquerque, NM) and Dr. Mary Beth Kirkham in the Department of Agronomy at Kansas State University (Manhattan, KS) for their valuable feedback associated with previous drafts of the manuscript.

${ }^{1}$ To whom reprint requests should be addressed; e-mail rcloyd@ksu.edu.
1990; Gillespie and Menzies, 1993; Jarvis et al., 1993).

Currently, insecticides applied as drenches to the growing medium are an effective management strategy against fungus gnat larvae (Hamlen and Mead, 1979; Lindquist, 1994; Lindquist et al., 1985). However, as a result of the limited number of insecticides registered for use in greenhouses, and the costs associated with development and registration of new insecticides (Lewis, 1977), it is important to judiciously use the currently available compounds (Lindquist et al., 1985). Biological control agents such as the rove beetle, Dalotia coriaria Kraatz (Coleoptera: Staphylinidae), have been shown to be an effective predator against fungus gnat larvae (Carney et al., 2002; Echegaray, 2012). However, a number of insecticides are directly and indirectly harmful to rove beetles (Cloyd et al., 2009). Consequently, physical barriers may be a long-term management strategy that could also be used with biological control agents (Banks, 1976).

Physical barriers are used to alter the environment so as to make it inaccessible to insect pests (Banks, 1976). There are a number of benefits associated with physical barriers such as compatibility with other insect pest management strategies including biological control and minimal impact on the environment (Boiteau, 2002). Nonetheless, physical barriers do not reduce an insect population immediately, which typically happens with most insecticides (Boiteau, 2002). A physical barrier could be placed on the surface of the growing medium to inhibit adult fungus gnat emergence or possibly reduce adult female egg-laying or egg survival (Cloyd et al., 2007a), whereas rove beetles feed on fungus gnat larvae in the growing medium. Physical barriers have been evaluated as a pest management strategy against insect pests, specifically the fungus gnat, Bradysia sp. nr. coprophila (Cloyd et al., 2007a).

Previous research by Cloyd et al. (2007a) evaluated the effect of dry and moist diatomaceous earth and sand as a physical barrier against fungus gnats. Diatomaceous earth affects insects either by removing or absorbing oils and waxes on the outer insect cuticle or by abrading the cuticle causing extensive moisture loss leading to desiccation. However, when diatomaceous earth becomes moist, it loses any abrasive properties (Korunic, 1998). Cloyd et al. (2007a) determined that both dry and moist diatomaceous earth and sand formed cracks or air pockets over time, which decreased their ability to negatively affect fungus gnats. This suggests that diatomaceous earth and sand may not be effective physical barriers.

Despite this, there are other materials that may act as physical barriers against fungus gnats such as Growstones ${ }^{\mathrm{TM}}$ (Growstone, Inc., Albuquerque, NM). Growstones ${ }^{\mathrm{TM}}$ aggregates are processed from $100 \%$ recycled glass and are primarily used as a hydroponic growing substrate in which plants are inserted into containers containing Growstones ${ }^{\mathrm{TM}}$ aggregates. A nutrient solution is applied to the container. Growstones ${ }^{\mathrm{TM}}$ aggregates are lightweight and can be manufactured into different particle sizes (Evans, 2011). It is possible that Growstones ${ }^{\mathrm{TM}}$ aggregates may serve as a physical barrier against fungus gnats in greenhouses. Therefore, the objectives of this study were 3-fold: 1) to determine the direct effect of Growstones ${ }^{\mathrm{TM}}$ aggregates applied to the growing medium surface on fungus gnat adult emergence; 2) to assess the indirect effect of Growstones ${ }^{\mathrm{TM}}$ aggregates placed on the growing medium surface on female egglaying and/or egg survival and subsequent adult emergence; and 3) to determine if using rove beetle, Dalotia coriaria, adults in conjunction with Growstones ${ }^{\mathrm{TM}}$ is synergistic in affecting fungus gnat adult emergence.

\section{Materials and Methods}

Fungus gnat colony. Laboratory-reared colonies of the fungus gnat, Bradysia sp. nr. coprophila, were located in the Department of Entomology at Kansas State University (Manhattan, KS) and maintained in 8.0-L plastic containers with tight-sealing lids. Openings $(\approx 15 \mathrm{~cm}$ square) were cut in the lids and then insect screening [ $50 \times 24(0.2 \times$ $0.8 \mathrm{~mm}$; Greentek, Edgerton, WI)] was hotglued to the lids to allow for ventilation. The 
growing medium inside the containers was Sunshine LC1 Professional Growing Mix (Sun Gro Horticulture, Inc., Bellevue, WA) consisting of Canadian sphagnum peatmoss, coarse perlite, starter nutrient charge (with gypsum), and dolomitic limestone. The laboratoryreared colonies were maintained at $24 \pm 3{ }^{\circ} \mathrm{C}$, $50 \%$ to $60 \%$ relative humidity, and a $14: 10$ (light:dark) -h photoperiod.

Rove beetle colony. Laboratory-reared colonies of the rove beetle, Dalotia coriaria, were located in the Department of Entomology at Kansas State University with colonies also maintained in $8.0-\mathrm{L}$ plastic containers with tight-sealing lids (see above) containing Sunshine LC1 Professional Growing Mix at $24 \pm 2{ }^{\circ} \mathrm{C}, 30 \%$ to $60 \%$ relative humidity, and a 0:24 (light:dark) -h photoperiod.

Deli containers. Approximately 10 holes were inserted into the bottom of circular 473-mL polypropylene deli containers $(8.0 \mathrm{~cm}$ bottom diameter, $11.0 \mathrm{~cm}$ top diameter, and $7.5 \mathrm{~cm}$ height) (Fabri-Kal Corp., Kalamazoo, MI) and insect screening was hot-glued to the bottom of each container so the container could be watered through capillary action. All deli containers were prepared with $\approx 80 \mathrm{~g}$ of Sunshine LC1 Professional Growing Mix growing medium $24 \mathrm{~h}$ before infesting with fungus gnat larvae or releasing adult fungus gnats (males and females). For all experiments (described below), the deli containers with tight-sealing lids, modified with insect screening to prevent fungus gnat adults from escaping and also allow for ventilation, were maintained in an environmental growth chamber (Adaptis CMP 6010; Conviron, Winnipeg, Manitoba, Canada) set at $24 \pm 2{ }^{\circ} \mathrm{C}$ and a 0:24 (light:dark) -h photoperiod.

Bottom-up experiments. These experiments, which focused on fungus gnat larvae, were conducted to determine the effect of Growstones $^{\mathrm{TM}}$ aggregates on fungus gnat larval movement and subsequently adult emergence. Fungus gnat larvae were obtained by placing a fungus gnat-inoculated growing medium sample $(\approx 10 \mathrm{~g})$ into a $50 \times 15-\mathrm{mm}$ glass petri dish using a spatula. Water was added to the growing medium and 20 fungus gnat larvae (second and third instar) were collected using a $150-\mathrm{mm}$ disposable flint glass non-sterile Pasteur pipette and then placed in a $50 \times 15-\mathrm{mm}$ glass petri dish filled with 8 to $10 \mathrm{~mL}$ of water. Larvae were counted under a stereomicroscope (Nikon SMZ-U; Fryer Comp., Huntley, IL) and then the entire contents were poured into a deli container filled with growing medium as described previously. After infesting the deli containers with fungus gnat larvae, the containers were placed into the environmental growth chamber set at $24 \pm 2{ }^{\circ} \mathrm{C}$ and a 0:24 (light:dark) -h photoperiod for $24 \mathrm{~h}$.

Expt. 1: Effect of three different sizes of Growstones $^{\mathrm{TM}}$ aggregates on fungus gnat adult emergence. Three different particle sizes of Growstones ${ }^{\mathrm{TM}}$ (treatments) aggregates were evaluated: small $(2.0 \mathrm{~mm})$, medium (no size available), and large $(10.0 \mathrm{~mm})$. A control with no Growstones ${ }^{\mathrm{TM}}$ was also included. A single layer (between 2.0 and $10.0 \mathrm{~mm}$ ) of each treatment was placed on the surface of the growing medium that was previously infested with fungus gnat larvae. There were 10 replications per treatment. In addition, 70 $\mathrm{mL}$ of water was added to the containers $24 \mathrm{~h}$ after applying the treatments to maintain growing medium moisture and ensure fungus gnat larval survival. As needed, water was poured into a dish placed at the base of each container, which allowed the growing medium to be moistened constantly through capillary action. A $2.5 \times 2.5$-cm yellow sticky card was affixed to the underside of the lid of the deli containers to capture emerging fungus gnat adults. The total number of adults captured was recorded $19 \mathrm{~d}$ after the Growstones ${ }^{\mathrm{TM}}$ treatments had been applied. For this experiment, and subsequent experiments, all the treatments were randomized within the environmental growth chamber.

Expt. 2: Effect of two thicknesses of Growstones $^{\mathrm{TM}}$ aggregates on fungus gnat adult emergence. Three treatments $[3.18-\mathrm{cm}$ Growstones $^{\mathrm{TM}}$ layer, 1.27-cm Growstones ${ }^{\mathrm{TM}}$ layer, and no Growstones ${ }^{\mathrm{TM}}$ (control)] of small $(2.0 \mathrm{~mm})$ Growstones ${ }^{\mathrm{TM}}$ aggregates were placed on the surface of the growing medium. There were 10 replications per treatment. Containers were maintained in the environmental growth chamber (see above) and water was added, as needed, into a dish placed at the base of each container. This moistened the growing medium through capillary action. After $7 \mathrm{~d}$, a $2.5 \times$ $2.5-\mathrm{cm}$ yellow sticky card was attached to the underside of the lid of each deli container to capture adult fungus gnats on emergence. The total number of fungus gnats captured on the yellow sticky card was recorded daily for $9 \mathrm{~d}$ after the first adult fungus gnat was observed.

Expt. 3: Effect of using rove beetle, Dalotia coriaria, adults with two thicknesses of Growstones ${ }^{\mathrm{TM}}$ aggregates on adult fungus gnat emergence. There were six treatments associated with the small $(2.0 \mathrm{~mm})$ Growstones ${ }^{\mathrm{TM}}$ aggregates: $3.18-\mathrm{cm}$ Growstones ${ }^{\mathrm{TM}}$ layer and five rove beetle adults, $3.18-\mathrm{cm}_{\text {Growstones }}{ }^{\mathrm{TM}}$ layer, $1.27-\mathrm{cm}_{\text {Growstones }}{ }^{\mathrm{TM}}$ layer and five rove beetle adults, $1.27-\mathrm{cm}$ Growstones ${ }^{\mathrm{TM}}$ layer, five rove beetle adults, and control (no Growstones $^{\mathrm{TM}}$ or rove beetle adults). There were 10 replications per treatment. Rove beetle adults ( 24 to $48 \mathrm{~h}$ old) were released into the designated containers $24 \mathrm{~h}$ after the growing medium was infested with fungus gnat larvae and then $24 \mathrm{~h}$ later the Growstones ${ }^{\mathrm{TM}}$ treatments were placed on the surface of the growing medium. There were five replications per treatment. The experimental procedures afterward were similar to those described previously. Seven days after the rove beetle adults were added, a $2.5 \times 2.5-\mathrm{cm}$ yellow sticky card was attached to the underside of the lid of each deli container to capture adult fungus gnats on emergence. The number of adults captured was determined $19 \mathrm{~d}$ after the Growstones ${ }^{\mathrm{TM}}$ treatments had been applied. After the number of captured fungus gnat adults was recorded, the growing medium in each deli container was sieved to quantify the number of rove beetles present at the end of the experiment.
Top-down experiments. These experiments focused on the behavior of fungus gnat adults and were conducted to assess fungus gnat egg-laying capacity or egg survival. The process involved fungus gnat eggs hatching, larvae migrating through the Growstones $^{\mathrm{TM}}$ layer to reach the growing medium to feed, and then migrating back through the Growstones ${ }^{\mathrm{TM}}$ layer to pupate and emerge as adults. Adult fungus gnats (males and females) were collected from the main colony and gender was determined using a stereomicroscope to form mating pairs. Fungus gnat adults were maintained separately in a 9-dram plastic vial $24 \mathrm{~h}$ before being released into the deli containers.

Expt. 4: Effect of three thicknesses of Growstones $^{\mathrm{TM}}$ aggregates applied to the growing medium surface on fungus gnat egg survival. There were three treatments based on thickness $(0.63 \mathrm{~cm}, 1.27 \mathrm{~cm}$, and $1.90 \mathrm{~cm})$ of the small $(2.0 \mathrm{~mm})$ Growstones ${ }^{\mathrm{TM}}$ aggregates. A control with no Growstones ${ }^{\mathrm{TM}}$ was also included. The treatments were applied to the surface of the growing medium in the deli containers. There were 10 replications per treatment. Pairs of fungus gnat adults (males and females) were collected (as described previously) and maintained in a vial for $24 \mathrm{~h}$ before a single mated female was released into the designated containers. After 2 weeks, a $2.5 \times 2.5-\mathrm{cm}$ yellow sticky card was affixed to the underside of the deli container lid to capture fungus gnat adults on emergence. The total number of adults captured was recorded $28 \mathrm{~d}$ after initially releasing adults into the deli containers. An indirect assessment of egg survival was based on the number of fungus gnat adults captured on the yellow sticky cards.

Expt. 5: Effect of two thicknesses of Growstones $^{\mathrm{TM}}$ aggregates applied to the growing medium surface on fungus gnat adult emergence. There were two treatments based on two thicknesses $(3.18$ and $1.27 \mathrm{~cm})$ of the small $(2.0 \mathrm{~mm})$ Growstones ${ }^{\mathrm{TM}}$ aggregates. A control treatment with no Growstones $^{\mathrm{TM}}$ was also included. There were 10 replications per treatment. The treatments were applied to the growing medium surface of the deli containers. Fungus gnat adult mating pairs (males and females) were collected and placed into a 9-dram vial for $24 \mathrm{~h}$ and then the female was released into each deli container. Before releasing the fungus gnats, $100 \mathrm{~mL}$ of water was added to the deli containers with Growstones ${ }^{\mathrm{TM}}$. A $2.5 \times$ $2.5-\mathrm{cm}$ yellow sticky card was attached to the lid underside of each deli container to capture emerging adults. The total number of fungus gnat adults captured was recorded $11 \mathrm{~d}$ after the first fungus gnat adult was observed.

Statistical analysis. Data from each experiment (1 through 5) were analyzed using SAS Statistical Software Program Version 9.2 (SAS Institute, 2002) in a one-way analysis of variance with the number of fungus gnat adults captured on the yellow sticky cards the primary response variable. When a significant effect of the response 
variable was detected, multiple comparisons were conducted using Tukey's least significant means test at $P \leq 0.05$.

\section{Results}

Results from Expt. 1 are presented in Figure 1. There was no significant difference $(F=1.27 ; \mathrm{df}=3,39 ; P=0.2995)$ among the Growstones $^{\mathrm{TM}}$ treatments based on the mean number of fungus gnat adults that emerged from the growing medium associated with the small $(2.0 \mathrm{~mm})$, medium, or large $(10.0 \mathrm{~mm})$ Growstones $^{\mathrm{TM}}$ aggregates. Each treatment had greater than 18 fungus gnat adults captured on the yellow sticky cards. However, this only entailed a single layer of a porous and irregular-shaped aggregate type substrate on the growing medium surface, which had no direct effect as a physical barrier. For Expt. 2, there was a significant difference among treatments $(F=6.5 ; \mathrm{df}=2,29 ; P=0.0049)$ on the final assessment date, which was $9 \mathrm{~d}$ after the initial observation of fungus gnat adults emerging. Fewer fungus gnat adults emerged $(12.6 \pm 1.2$; mean \pm SEM) from the thickest Growstones $^{\mathrm{TM}}$ treatment (3.18-cm layer) compared with the control treatment (18.4 \pm 0.6) with no Growstones ${ }^{\mathrm{TM}}$ (Fig. 2). In addition, the thickest layer of Growstones ${ }^{\mathrm{TM}}$ delayed fungus gnat adult emergence over the 9-d evaluation period (Fig. 3). There was no significant difference between Treatment $1\left(3.18-\mathrm{cm}\right.$ layer of Growstones $\left.{ }^{\mathrm{TM}}\right)$ and Treatment $2\left(1.27-\mathrm{cm}\right.$ layer of Growstones $\left.{ }^{\mathrm{TM}}\right)$. Also, we observed fungus gnat larvae (fourth instar) migrating through the layers of the Growstones $^{\mathrm{TM}}$ aggregates (Fig. 4). The results from Expt. 3 indicated a significant difference among the treatments $(F=5.78 ; \mathrm{df}=5$, $29 ; P=0.0012)$; however, there was no significant difference between the treatments associated with the same Growstones ${ }^{\mathrm{TM}}$ thickness with or without five rove beetle adults (Fig. 5). The mean number of rove beetles recovered (adults and larvae) from Treatments 1,3 , and 5 was $3.6 \pm 0.4,4.6 \pm 1.2$, and $5.8 \pm 1.5$, respectively, with $\approx 90 \%$ of the recovered rove beetles being adults. Significantly fewer $(F=5.23 ; \mathrm{df}=3,19 ; P=0.0105)$ adult fungus gnats emerged from the growing medium with the thickest layer $(1.90 \mathrm{~cm})$ of small $(2.0 \mathrm{~mm})$ Growstones ${ }^{\mathrm{TM}}$ aggregates indicating an indirect effect on egg survival associated with Expt. 4. On average, $88.0 \pm$ 20.4 fungus gnat adults were captured on yellow sticky cards in the control treatment, whereas $14.6 \pm 8.8$ fungus gnat adults were captured in containers with the $1.90-\mathrm{cm}$ Growstones $^{\mathrm{TM}}$ layer. The other thicknesses $(0.63$ and $1.27 \mathrm{~cm})$ were not significantly different from the control (no Growstones $^{\mathrm{TM}}$ ) with $44.0 \pm 13.0$ and $37.8 \pm 7.3$ fungus gnat adults captured on the yellow sticky cards, respectively (Fig. 6). For Expt. 5 , there were significantly $(F=4.53 ; \mathrm{df}=2$, 27; $P=0.02$ ) fewer fungus gnat adults captured on the yellow sticky cards $(53.5 \pm$ 9.0) associated with the thickest Growstones ${ }^{\mathrm{TM}}$ layer $(3.18 \mathrm{~cm})$ than the control $(94.1 \pm 7.7)$ (Fig. 7).

\section{Discussion}

Small Growstones ${ }^{\mathrm{TM}}$ aggregates at the thickest layer $(3.18 \mathrm{~cm})$ resulted in significantly fewer adults emerging in deli containers compared with the control (no Growstones ${ }^{\mathrm{TM}}$ ). In addition, the thickest layer of Growstones ${ }^{\mathrm{TM}}$ aggregates delayed fungus gnat adult emergence. This delay in emergence was probably the result of the additional layer of Growstones $^{\mathrm{TM}}$ that fungus gnat larvae had to migrate through to pupate and egress as adults.

The use of the rove beetle, Dalotia coriaria, against fungus gnat larvae has been shown to be an effective pest management strategy (Carney et al., 2002; Echegaray, 2012). Banks (1976) proposed that a benefit of physical barriers would be minimal direct harm to biological control agents, compared with insecticides, which may be directly or indirectly harmful to biological control agents including D. coriaria (Cloyd et al., 2009; Echegaray and Cloyd, 2012; Jandricic et al., 2006). Results from our study, however, indicate no synergistic effect associated with using D. coriaria in conjunction with Growstones $^{\mathrm{TM}}$. The Growstones ${ }^{\mathrm{TM}}$ did not negatively affect rove beetle survival based on the number of adults and larvae recovered (refer to "Results"), which is likely the result of the rove beetles remaining in the growing medium and not migrating through the Growstones $^{\mathrm{TM}}$ layer. However, the reason there was no benefit of including the rove beetle may be that fungus gnat larvae escaped exposure from rove beetle adults by migrating through the Growstones ${ }^{\mathrm{TM}}$ layer to pupate, which was evident in the bottom-up experiments. Regardless, it might be warranted to study the interaction between the Growstones ${ }^{\mathrm{TM}}$ aggregates and the rove beetle adult.

The top-down experiments were primarily designed to indirectly assess fungus gnat egg survival. Previous research showed that females prefer to lay eggs in crevices within the growing medium where the humidity is higher than the growing medium surface (Binns, 1973). For the top-down experiments, the addition of Growstones ${ }^{\mathrm{TM}}$ may have created a "dry environment" for fungus

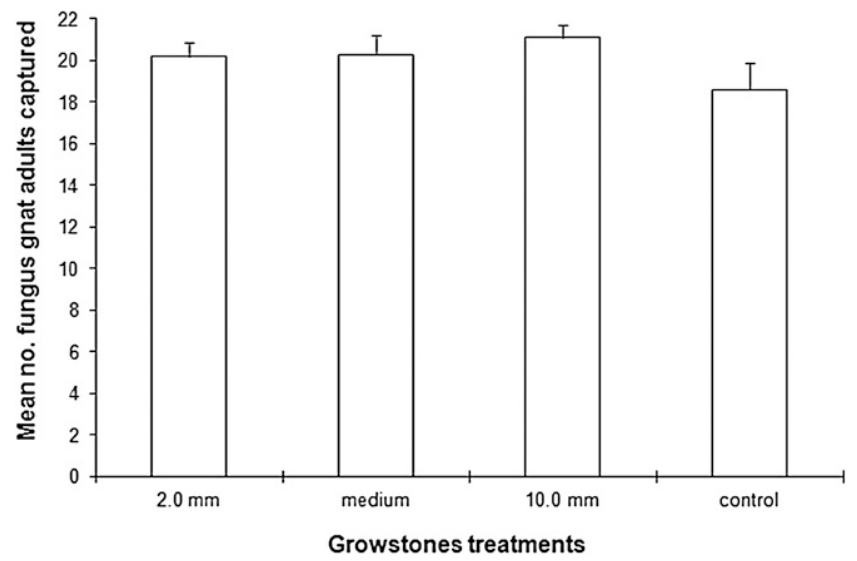

Fig. 1. Mean number of fungus gnat, Bradysia sp. nr. coprophila, adults captured on yellow sticky cards $(2.5 \times 2.5 \mathrm{~cm})$ associated with each treatment (small or $2.0 \mathrm{~mm}$, medium, and large or $10.0 \mathrm{~mm}$ ) of the different Growstones ${ }^{\mathrm{TM}}$ aggregates (Growstone, Inc., Albuquerque, NM). Vertical lines represent the SEM.

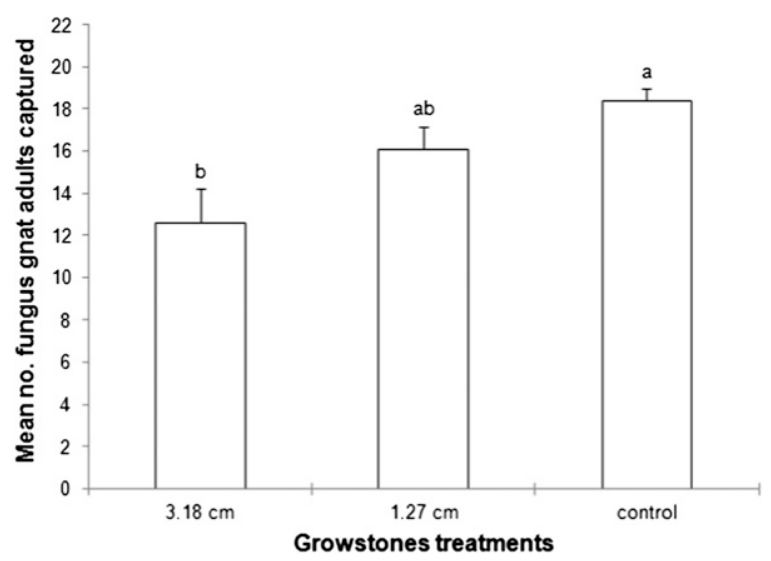

Fig. 2. Mean number of fungus gnat, Bradysia sp. nr. coprophila, adults captured on yellow sticky cards $(2.5 \times 2.5 \mathrm{~cm})$ associated with two thicknesses of small $(2.0 \mathrm{~mm})$ Growstones $^{\mathrm{TM}}$ aggregates (Growstone, Inc., Albuquerque, NM) and a control (no Growstones ${ }^{\mathrm{TM}}$ ). Bars with the same lowercase letter are not significantly different from each other $(P \geq 0.05)$ based on Tukey's least significant means test. Vertical lines represent the SEM. 


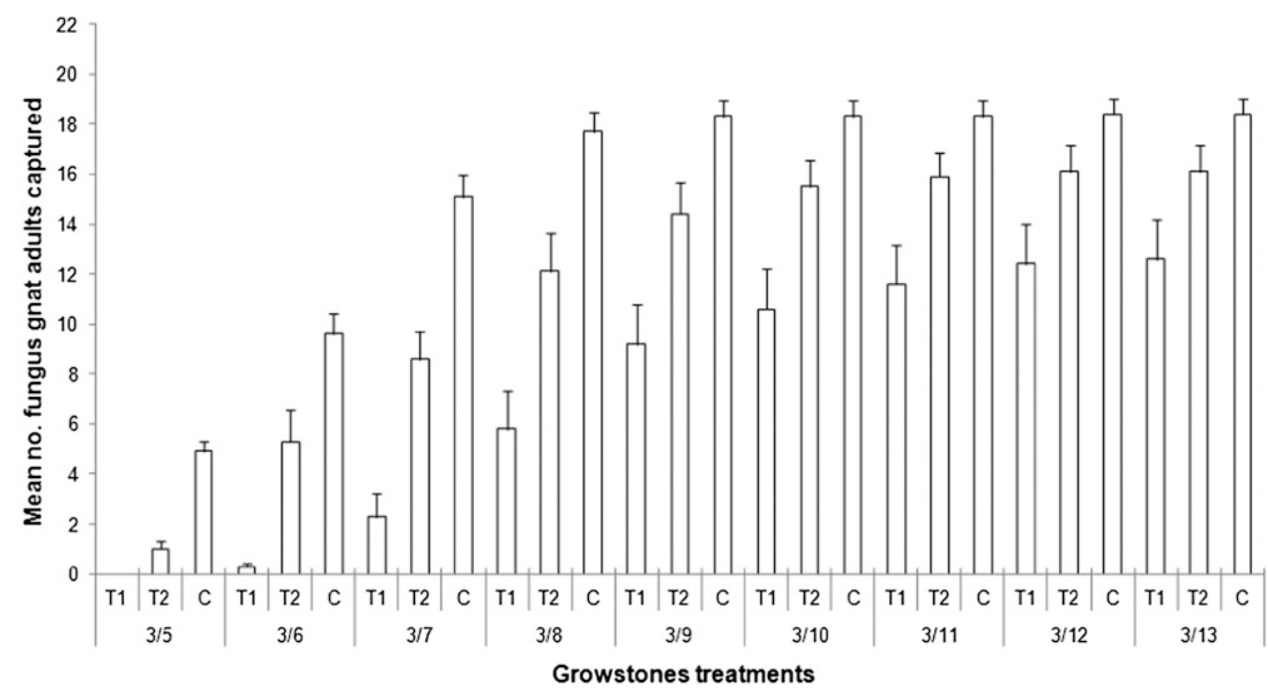

Fig. 3. Mean number of fungus gnat, Bradysia sp. nr. coprophila, adults captured on yellow sticky cards $(2.5 \times 2.5 \mathrm{~cm})$ associated with two thicknesses $(\mathrm{T} 1=$ $3.18 \mathrm{~cm}$ and $\mathrm{T} 2=1.27 \mathrm{~cm})$ of small $(2.0 \mathrm{~mm})$ Growstones ${ }^{\mathrm{TM}}$ aggregates (Growstone, Inc., Albuquerque, NM), and a control $\left(\mathrm{C}=\right.$ no Growstones $\left.{ }^{\mathrm{TM}}\right)$ over a $9-\mathrm{d}$ evaluation period (5 Mar. 2013 to 13 Mar. 2013). Vertical lines represent the SEM.

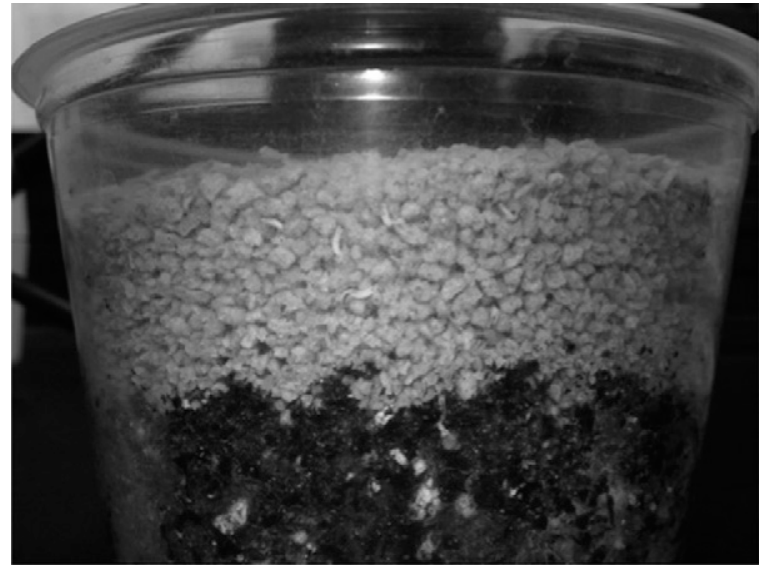

Fig. 4. Close-up of fungus gnat (Bradysia sp. nr. coprophila) fourth instar larvae migrating through a 3.18-cm layer of Growstones ${ }^{\mathrm{TM}}$ aggregates (Growstone, Inc., Albuquerque, NM) in a $473-\mathrm{mL}$ deli container.

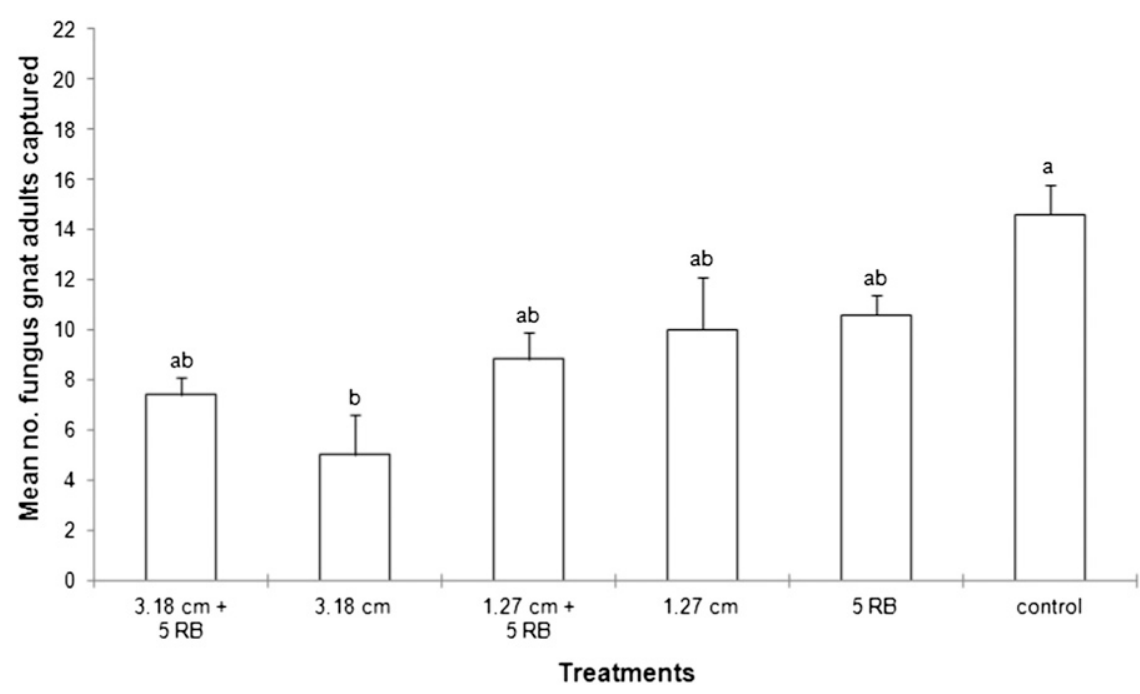

Fig. 5. Mean number of fungus gnat, Bradysia sp. nr. coprophila, adults captured on yellow sticky cards $(2.5 \times 2.5 \mathrm{~cm})$ associated with rove beetle $(\mathrm{RB})$, Dalotia coriaria, adults and two thicknesses $(1.27$ and $3.18 \mathrm{~cm})$ of small $(2.0 \mathrm{~mm})$ Growstones ${ }^{\mathrm{TM}}$ aggregates (Growstone, Inc., Albuquerque, NM). There were six treatments including a control (no Growstones ${ }^{\mathrm{TM}}$ or rove beetles). Bars with the same lowercase letter are not significantly different from each other $(P \geq 0.05)$ based on Tukey's least significant means test. Vertical lines represent the SEM. gnats. In fact, we initially observed high mortality (nearly $100 \%$ ) within the first $24 \mathrm{~h}$ for both males and females after releasing them into the deli containers (A. Raudenbush, personal observation). So, to conduct the experiment, $100 \mathrm{~mL}$ of water was added to each deli container before releasing the fungus gnats. We used subirrigation to maintain constant moisture of the growing medium in each deli container that resulted in the Growstones $^{\mathrm{TM}}$ absorbing water from the growing medium over time. Moistened Growstones ${ }^{\mathrm{TM}}$ were darker in color compared with dry Growstones $^{\mathrm{TM}}$ (A. Raudenbush, personal observation), which indicated that they had absorbed water. In fact, Evans (2011) reported that Growstones ${ }^{\mathrm{TM}}$ aggregates are capable of absorbing moisture with a water-holding capacity of $34.3 \%$, which is greater than perlite and parboiled rice hulls. Therefore, the moist Growstones $^{\top \mathrm{M}}$ may have provided a more favorable environment for fungus gnats to survive.

Significantly fewer fungus gnat adults emerged in the top-down experiments associated with the thickest layer $(3.18 \mathrm{~cm})$ of Growstones $^{\mathrm{TM}}$ compared with the control. It is possible that fungus gnat females laid fewer eggs in or on the Growstones ${ }^{\mathrm{TM}}$ layers. Meers and Cloyd (2005) reported that female fungus gnats prefer to lay eggs in certain soilless growing media. The growing medium used in our study was Sunshine LC1, which is a preferred growing medium for fungus gnat females to lay eggs (Meers and Cloyd, 2005), so any characteristics associated with the growing medium such as the release of volatiles that may be repellent (Cloyd et al., 2007b) was not a factor that would have inhibited female fungus gnats from laying eggs. Based on the results from the bottom-up experiments, we know that fungus gnat larvae survived the Growstones ${ }^{\mathrm{TM}}$ treatments. Therefore, any effects in regard to the topdown experiments were likely associated with egg mortality or fewer eggs being laid 


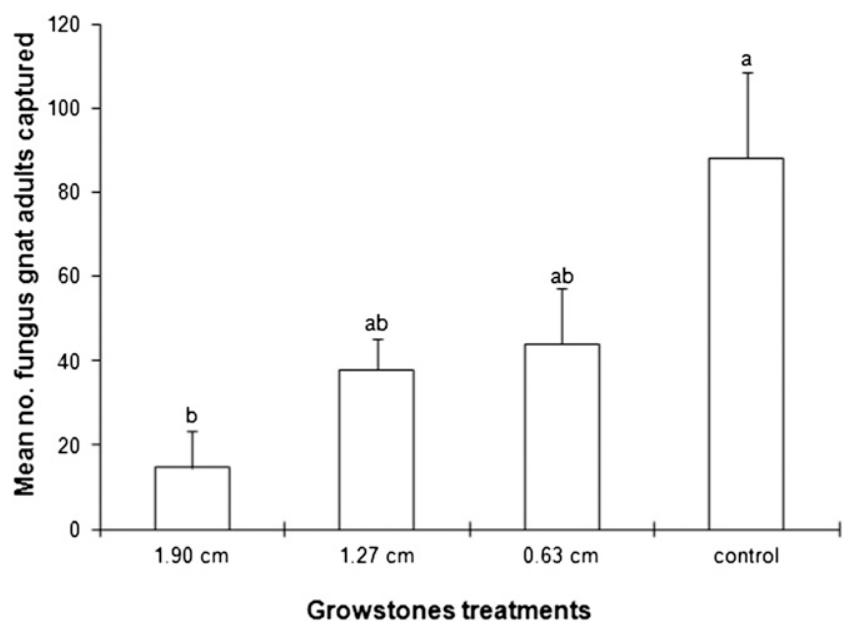

Fig. 6. Mean number of fungus gnat, Bradysia sp. nr. coprophila, adults captured on yellow sticky cards $(2.5 \times 2.5 \mathrm{~cm})$ associated with each treatment using different thicknesses $(0.63,1.27$, and $1.90 \mathrm{~cm})$ of the small $(2.0 \mathrm{~mm})$ Growstones ${ }^{\mathrm{TM}}$ aggregates (Growstone, Inc., Albuquerque, NM) and a control (no Growstones ${ }^{\mathrm{TM}}$ ) when a single fungus gnat female was released into each $473-\mathrm{mL}$ deli container. Bars with the same lower case letter are not significantly different from each other $(P \geq 0.05)$ based on Tukey's least significant means test. Vertical lines represent the sEM.

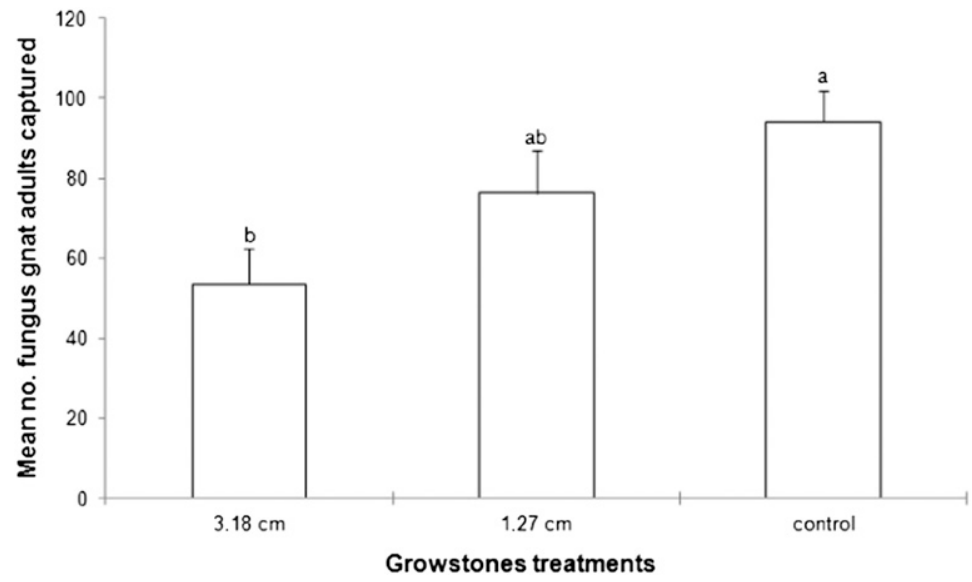

Fig. 7. Mean number of fungus gnat, Bradysia sp. nr. coprophila, adults captured on yellow sticky cards $(2.5 \times 2.5 \mathrm{~cm})$ associated with two thicknesses $(1.27$ and $3.18 \mathrm{~cm})$ of small $(2.0 \mathrm{~mm})$ Growstones $^{\mathrm{TM}}$ aggregates (Growstone, Inc., Albuquerque, $\mathrm{NM}$ ) and a control (no Growstones ${ }^{\mathrm{TM}}$ ) with a single fungus gnat pair (male and female) released into each $473-\mathrm{mL}$ deli container. Bars with the same lowercase letter are not significantly different from each other $(P \geq 0.05)$ based on Tukey's least significant means test. Vertical lines represent the SEM.

by the females. The thickness of the Growstones $^{\mathrm{TM}}$ layer may have affected the ability of the females to lay eggs, resulting in fewer adults emerging. Another possibility is that females laid eggs, but there was low egg survival as a result of the "dry environment" affiliated with the Growstones ${ }^{\mathrm{TM}}$ treatment. Eggs of many insects are very susceptible to desiccation under dry growing medium conditions (Shililu et al., 2004; Villani and Wright, 1990). As such, further research is needed to determine how Growstones ${ }^{\mathrm{TM}}$ aggregates influence female egg-laying and egg survival.

Furthermore, it is important to note that a physical barrier is designed to gradually reduce insect pest populations over time, unlike contact insecticides, which diminish insect populations immediately (Boiteau, 2002). This study has shown that Growstones ${ }^{\mathrm{TM}}$ delayed fungus gnat adult emergence over time, increases their exposure to insecticide applications resulting in higher mortality, whereas in the growing medium, the larvae can hide in cracks and crevices, thus escaping exposure to insecticides or the insecticide may be absorbed by any organic matter present in the growing medium (Castro and Yoshida, 1974; Leenheer and Ahlrichs, 1971), thus preventing contact with fungus gnat larvae. Both of these scenarios might result in a decrease in insecticide efficacy. Therefore, the use of Growstones ${ }^{\mathrm{TM}}$ may in actuality lead to a reduction in the number of insecticide applications required against fungus gnat larvae, which is a cost-savings in labor and lessens the risk of insecticide resistance.

\section{Literature Cited}

Banks, H.J. 1976. Physical control of insects-Recent developments. J. Aust. Entomol. Soc. 15:89-100

Binns, E.S. 1973. Laboratory rearing, biology and chemical control of the mushroom sciarid Lycoriella auripila (Diptera: Lycoriidae). Ann. Appl. Biol. 73:119-126.

Boiteau, G. 2002. Physical barriers for the control of insect pests, p. 616-618. In: Pimentel, D. (ed.). Encyclopedia of pest management. Marcel Dekker Inc., New York, NY.

Carney, V.A., J.C. Diamond, G.D. Murphy, and D. Marshall. 2002. The potential of Athena coriaria Kraatz (Coleoptera: Staphylinidae), as a biological control agent for use in greenhouse crops. International Organization for Biological Control/West Palaearctic Regional Section Bull. 25:37-40.

Castro, T.F. and T. Yoshida. 1974. Effect of organic matter on the biodegradation of some organochlorine insecticides in submerged soils. Soil Sci. Plant Nutr. 20:363-370

Cloyd, R.A. 2000. Fungus gnats and shore fly management strategies: Panel discussion, p. 57-59. In: King, A.I. and I.D. Greene (eds.). Proc. for the 16th Conference on Insect and Disease Management on Ornamentals, 19-21 Feb. 2000, San Jose, CA Society of American Florists, Alexandria, VA.

Cloyd, R.A., A. Dickinson, and K.E. Kemp. 2007a. Effect of Diatomaceous earth and Trichoderma harzianum T-22 (Rifai Strain KRL-AG2) on the fungus gnat Bradysia sp. nr. coprophila (Diptera: Sciaridae). J. Econ. Entomol. 100:1353-1359.

Cloyd, R.A., A. Dickinson, R.A. Larson, and K.A. Marley. 2007b. Effect of growing media and their constituents on fungus gnat, Bradysia sp. nr. coprophila (Lintner) adults. Insect Sci. 14:467-475.

Cloyd, R.A., N.R. Timmons, J.M. Goebel, and K.E. Kemp. 2009. Effect of pesticides on adult rove beetle Athena coriaria (Coleoptera: Staphylinidae) survival in growing medium. J. Econ. Entomol. 102:1750-1758.

Dennis, D.J. 1978. Observations of fungus gnat damage to glasshouse curcubits. N.Z. J. Expt. Agr. 6:83-84.

Echegaray, E. 2012. Life history parameters of the rove beetle Atheta coriaria (Kraatz) and suitability as a biological control agent against the fungus gnat Bradysia sp. nr. coprophila (Lintner). $\mathrm{PhD}$ diss.,. Kansas State University, Manhattan, KS.

Echegaray, E.R. and R.A. Cloyd. 2012. Effects of reduced-risk pesticides and plant growth regulators on rove beetle (Coleoptera: Staphylinidae) adults. J. Econ. Entomol. 105:2097-2106.

Evans, M.R. 2011. Physical properties of and plant growth in peat-based root substrates containing glass-based aggregate, perlite, and parboiled fresh rice hulls. HortTechnology 21:30-34. 
Gardiner, R.B., W.R. Jarvis, and J.L. Shipp. 1990 Ingestion of Pythium spp. by larvae of the fungus gnat Bradysia impatiens (Diptera: Sciaridae). Ann. Appl. Biol. 116:205-212.

Gillespie, D.R. and J.G. Menzies. 1993. Fungus gnats vector Fusarium oxyspoorum f. sp. radicislycopersici. Ann. Appl. Biol. 123:539-544.

Hamlen, R.A. and F.W. Mead. 1979. Fungus gnat larval control in greenhouse plant production. J. Econ. Entomol. 9:538-549.

Jandricic, S., C.D. Scott-Dupree, A.B. Broadbent, C.R. Harris, and G. Murphy. 2006. Compatibility of Atheta coriaria with other biological control agents and reduced-risk insecticides used in greenhouse floriculture integrated pest management programs for fungus gnats. Can. Entomol. 138:712-722.

Jarvis, W.R., J.L. Shipp, and R.B. Gardiner. 1993. Transmission of Pythium aphanidermatum to greenhouse cucumber by the fungus gnat $\mathrm{Bra}$ dysia impatiens (Diptera: Sciaridae). Ann. Appl. Biol. 122:23-29.
Korunic, Z. 1998. Diatomaceous earths, a group of natural insecticides. J. Stored Prod. Res. 34:87-97.

Leenheer, J.A. and J.L. Ahlrichs. 1971. A kinetic and equilibrium study of the adsorption of carbaryl and parathion upon soil organic matter surfaces. Soil Sci. Soc. Amer. J. 35:700-705.

Lewis, C.J. 1977. The economics of pesticide research, p. 237-245. In: Cherrett, J.M. and G.R. Sager (eds.). Origins of pest, parasite, disease and weed problems. Oxford, Blackwell, UK.

Lindquist, R.K. 1994. Integrated management of fungus gnats and shoreflies, p. 58-67. In: Robb, K. (ed.). Proc. for the 10th conference on Insect and Disease Management on Ornamentals, 19 21 Feb. 1994, Dallas, TX. Soc. Amer. Florists, Alexandria, VA.

Lindquist, R.K., W.R. Faber, and M.L. Casey. 1985. Effect of various soilless root media and insecticides on fungus gnats. HortScience 20:358-360.

Meers, T.L. and R.A. Cloyd. 2005. Egg-laying preference of female fungus gnat Bradysia sp. nr. coprophila (Diptera: Sciaridae) on three different soilless substrates. J. Econ. Entomol. 98:1937-1942.

SAS Institute. 2002. SAS/STAT user's guide for personal computers, Version 9.1. SAS Institute, Cary, NC.

Shililu, J.I., W.B. Grueber, C.M. Mbogo, J.I. Githure, L.M. Riddiford, and J.C. Beier. 2004. Development and survival of Anopheles gambiae eggs in drying soil: Influence of the rate of drying, egg age, and soil type. J. Amer. Mosq. Control Assoc. 20:243-247.

Springer, T.L. 1995. Fungus gnat (Diptera: Sciaridae) feeding damage to legume seedlings. J. Kans. Entomol. Soc. 68:240-242.

Villani, M.G. and R.J. Wright. 1990. Environmental influences on soil macro arthropod behavior in agricultural systems. Annu. Rev. Entomol. 35:249-269.

Wilkinson, J.D. and D.M. Daugherty. 1970. The biology and immature stages of Bradysia impatiens (Diptera: Sciaridae). Ann. Entomol. Soc. Amer. 63:656-660. 